\title{
Pitting Corrosion Damage for Prediction Useful Life of Geothermal Turbine Blade
}

\author{
Cuevas-Arteaga $\mathrm{C}^{1}$, Rodriguez $\mathrm{JA}^{1, *}$, Clemente $\mathrm{CM}^{1}$, Rodríguez $\mathrm{JM}^{2}$, Mariaca $\mathrm{Y}^{1}$ \\ ${ }^{1}$ Centro de Investigación en Ingeniería y Ciencias Aplicadas, (CIICAp), UAEM, Cuernavaca, Morelos, Mexico \\ ${ }^{2}$ Centro Nacional de Investigación y Desarrollo Tecnológico \\ *Corresponding author: jarr@uaem.mx
}

Received December 02, 2014; Revised December 14, 2014; Accepted December 16, 2014

\begin{abstract}
In the last years, the power industry in México has suffered the consequences of some mechanisms of damage that reduce the efficiency in power generation. These mechanisms of damage originate problems in main components as rotors, nozzle blades and others due to losses of pressure, high vibrations, erosion and corrosion. By the type of work fluid, mixture of water-steam and brine rich in salts, geothermal turbines are in a high corrosion environment. The main forms of damage caused by corrosion in a geothermal turbine are crevice corrosion and pitting corrosion. The latter is a damage mechanism through which the useful life is affected. The blades of the last stage in low pressure (LP) in the geothermal turbines are exposed to corrosion by environment and high load cycles which cause failures by corrosion fatigue, crack initiation and crack propagations. In this work, a methodology for the analysis of the failure by pitting corrosion and its consequences in its useful life was obtained. From the results, it is possible to conclude that this corrosion may influence a mechanism of pitting corrosion, which precedence to stress corrosion cracking and corrosion fatigue.
\end{abstract}

Keywords: pitting corrosion, blades of geothermal turbine, useful life, damage mechanisms

Cite This Article: Cuevas-Arteaga C, Rodriguez JA, Clemente CM, Rodríguez JM, and Mariaca Y, "Pitting Corrosion Damage for Prediction Useful Life of Geothermal Turbine Blade." American Journal of Mechanical Engineering, vol. 2, no. 6 (2014): 164-168. doi: 10.12691/ajme-2-6-3.

\section{Introduction}

Different studies have been carried out on geothermal turbine blades for early damage detecting and useful life estimation [1]. Phenomena related aerodynamic instability cause changes in amplitude of vibrations. This instability produces failure by mechanical fatigue [2]. When the frequency of this aerodynamic instability and, external forces of excitation, coincide with one of the natural frequencies of the blades or group of blades, a condition known as resonance occurs affecting useful life of steam turbines. The environment and the work flow where energy is transformed present another two damage phenomena; erosion and corrosion [3]. The corrosion is a very costly damage mechanism that has a major impact on the economies of turbomachinery. There are two types of corrosion; mixed corrosion and localized corrosion. The development of damage due to localized corrosion on geothermal turbine surfaces involves complex interactions between deposits and electrolyte films [4].

Different studies show that corrosion process in the blades is induced by environment causing pit, local deformation and finally fatigue cracks [5]. Pitting corrosion or pitting is considered to be one of the main degradation mechanisms for many metallic materials subjected to corrosive environment. This corrosion mechanics leads to the crack initiation, crack growth and failure in stress corrosion cracking and under tensile stress in corrosion fatigue in geothermal turbine blades in L-0 stages of low pressure (LP). Blades of last stages present different problems that may contribute to the failure process, but the limited operational lifetimes are primarily attributed to corrosion pit, steam turbine corrosion and deposits' problems and solutions [6]. It is important for the development to analyze this behavior and control these mechanisms of degradation to create experimental and numerical models [7]. Experimental and numerical models are used to predict the damage and the useful life of geothermal turbine blades $[8,9]$.

The presence of corrosion pit reduces the fatigue life of the blades. Some models and statistical approaches provide an approximation of these types of damage mechanics and in some cases make it possible to calculate the useful life. In this work experimentally the corrosion rate of 410 stainless steel (410 SS) in presence of cracks and without crack as a function of time at different temperatures was determined.

Numerical models to determine the stress intensity factor were created and useful life was calculated. The damage process calculation consists in four phases: pitting nucleation, pit growth, short crack growth and long crack $[10,11,12]$.

\section{Experimental Models}


The blades' steel for this work was a martensitic grade $12 \%$ Cr-Steel. Table 1 shows the mechanical properties of the 410 SS and Figure 1 shows the dimensions of the specimen according to the specifications of the RB200 machine for fatigue[13]. These specimens were subjected to fatigue, according to ASTM E 647-88a [14].

Table 2 shows the frequency values and loading cycles to which the specimens were subjected to fatigue testing.

Table 1. Mechanical Properties 410 SS

\begin{tabular}{|c|c|c|c|c|}
\hline $\begin{array}{c}\text { Material } \\
\text { type }\end{array}$ & $\begin{array}{c}\text { UTS } \\
\mathrm{Pa}\end{array}$ & $\begin{array}{c}0.2 \% \\
\mathrm{~Pa}\end{array}$ & Elongation & Reduction Area \\
\hline $410 \mathrm{SS}$ & 689.47 & $551.58 \mathrm{E} 6$ & 12 & 40 \\
\hline
\end{tabular}

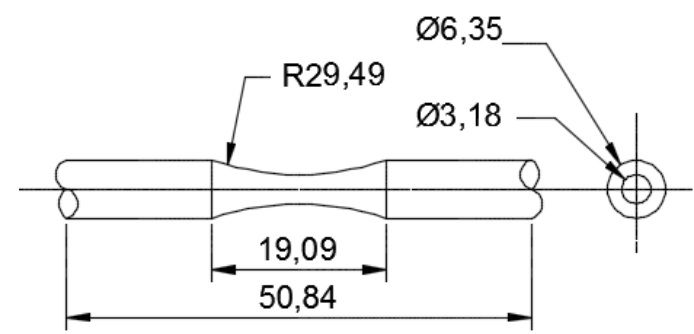

Figure 1. Dimensions of the specimens in mm, Solidworks ${ }^{\circledR}[13,14]$

Table 2. Frequency values and loading cycles specimens

\begin{tabular}{|c|c|c|c|}
\hline Specimen & Frequency & $\mathrm{N}_{\mathrm{f}}$ (Cycles) & Load $\mathrm{N}$ \\
\hline 1 & 28 & $5.0382 \times 10^{4}$ cycle & 1.5 \\
\hline 2 & 28 & $6.0216 \times 10^{4}$ cycle & 1.5 \\
\hline
\end{tabular}

The crack length was measured by means a Scanning Electron Microscopy (SEM) Figure 2 and Figure 3.

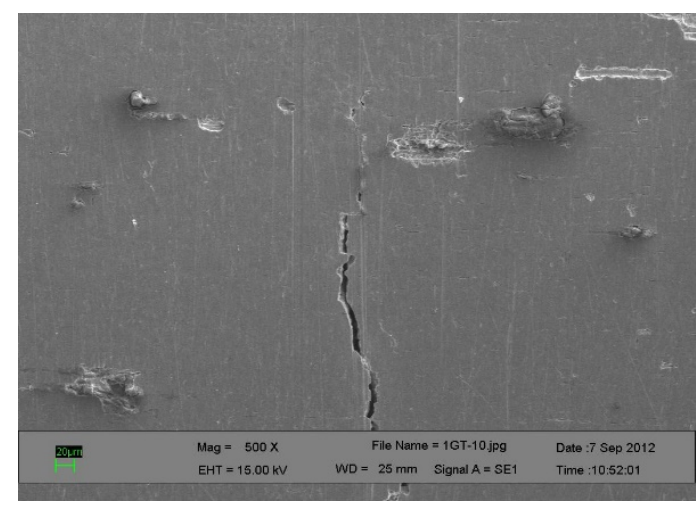

Figure 2. Dimension of the crack in the specimen

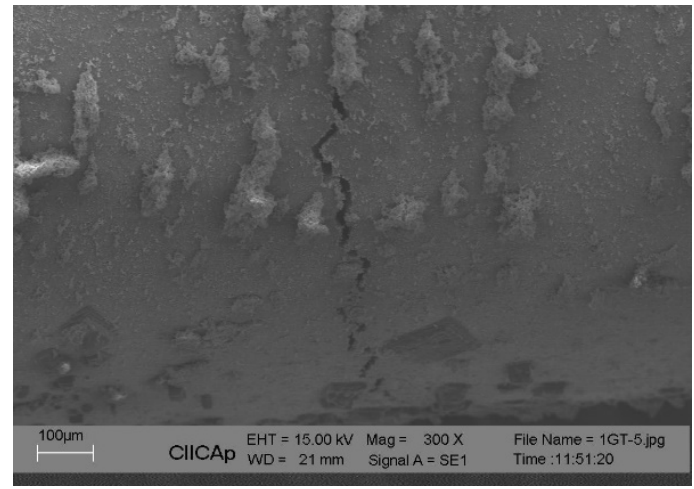

Figure 3. Dimension of the crack in the specimen after exposing

The presence of high content of sulfates and chlorides makes the solution extremely corrosive, especially for 410 $\mathrm{SS}$, in which the susceptibility to suffer localized corrosion has been observed. After exposing the specimens at $298^{\circ} \mathrm{K}$, Figure 3 and $363^{\circ} \mathrm{K}$ during five days, both specimens with and without corrosion products were analyzed by SEM and was is possible to obtain values for the modeling.

\section{Modeling}

The numerical, probabilistic and statistical models are used when some damage processes are difficult to predict; they assist to recreate some phenomena that would not be possible in an experimental form and with these the useful life of the mechanical components can be predicted. In the present study, the damage processes were calculated when aggressive environment leads the failure. The calculated damage process consists in four phases: pitting nucleation, pit growth, short crack growth and long crack $[15,16]$.

\subsection{Nucleation of Pitting $\left(t_{p n}\right)$}

The first phase in the damage process depends on factors such as: time, temperature, material, and current potential. The pit nucleation is obtained from experimental or physical observation of micrographs based on analysis in order to estimate the probability of pits' formation with equation 1 [17]

$$
\text { Probability }\{\mathrm{p}\}=0.725 \mathrm{p}^{-2.41}
$$

where $\mathrm{p}$ can take values from $1 . . . \mathrm{n}$, as a set of pits.

The morphology of the crack nucleating pits can be approximated by equivalent semi- elliptical crack with a depth of a $\boldsymbol{b}$ and a half-width of $\boldsymbol{a}$. Figure 4 [18].

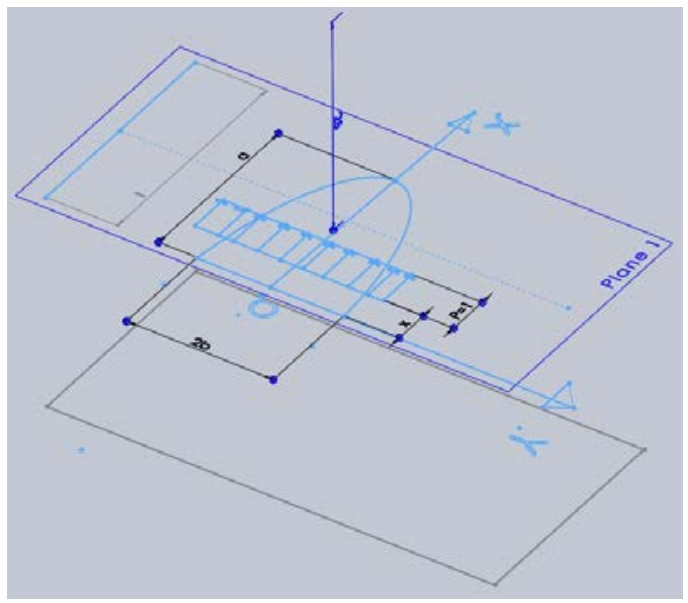

Figure 4. Semi elliptical crackSolidworks ${ }^{\circledR}[19]$

\subsection{Growth of Pitting}

The electrochemical process was present in the second phase where pits raised from localized corrosion. In this phase the blades present pits in their surface. To estimate the pit's growth time it is necessary to consider the semi elliptical shape. Table 3 shows deterministic values for calculated the time for pitting growth with the equation 2 $[17,19]$.

$$
t_{p g}=\frac{2 \pi n F_{p}}{3 M I_{p o} K}\left(C_{c i}{ }^{3}-C_{o}{ }^{3}\right) e^{\Delta H / R T}
$$


Where $\mathrm{c}_{\mathrm{ci}}$ is the critical size leading to crack nucleation and $\mathrm{c}_{0}$ is the initial pit size. Equation 4 indicates the growth time of the bite which depends on the set of pits in the surface of the blade.

Table 3. Deterministic variables

\begin{tabular}{|c|c|}
\hline Variable & Values \\
\hline Density $\left(\mathrm{g} / \mathrm{m}^{3}\right)$ & $\mathrm{\rho}=7.810^{3}$ \\
\hline Valence & $\mathrm{n}=3$ \\
\hline Molecular weight (g) & $\mathrm{M}=55.510^{-3}$ \\
\hline Faraday's constant (C/mol) & $\mathrm{F}=96514$ \\
\hline Activation Energy $(\mathrm{kJ} / \mathrm{mol})^{[15]}$ & $\Delta \mathrm{H}=3110^{3}$ \\
\hline Universal gas constant $(\mathrm{J} / \mathrm{mol} \mathrm{K})$ & $\mathrm{R}=8.314$ \\
\hline Temperature $(\mathrm{K})$ & $\mathrm{T}=363.15$ \\
\hline Applied stress (MPa) & $\Delta \mathrm{S}=834$ \\
\hline Frequency (cycles) & $\mathrm{f}=28$ \\
\hline Stress concentration factor & $\mathrm{k}_{\mathrm{t}}=3$ \\
\hline Short crack growth exponent $[14]$ & $\mathrm{m}_{\mathrm{sc}}=3.40$ \\
\hline Long crack growth exponent $[14]$ & $\mathrm{m}_{\mathrm{lc}}=3.40$ \\
\hline Specified critical crack size $(\mathrm{m})$ & $\mathrm{a}_{\mathrm{f}}=110^{-2}$ \\
\hline
\end{tabular}

\subsection{Short Crack Growth}

Microstructural processes are present on the third phase. The fracture mechanics play an important role on this phase. The Law of Paris is used to calculate the time of the short crack growth. However, the parameters involved are random variables dependent on experimental data. Therefore the short crack growth can be expressed by the following equations 3 and 4 [17]

$$
\begin{gathered}
\frac{d a}{d N}=C_{S C}(\Delta K)^{m_{S C}} \\
C_{C i}=\left(\frac{C p}{2 \pi C_{S C} f}\right)^{\frac{2}{m_{C S}+4}}\left(\frac{\Phi}{1.12 K_{t} \Delta \sigma \sqrt{\pi}}\right)^{\frac{2 m_{S C}}{m_{S C+4}}}
\end{gathered}
$$

The time for growth of short crack is given by equation 5 [17].

$$
t_{s c}=\frac{2}{\left(2-m_{S C}\right) f_{s C} \frac{2.2 K t \Delta \sigma^{m_{S C}}}{\sqrt{\pi}}}\left(a_{t h}^{1-\frac{m s c}{2}}-C_{c i}^{1-\frac{m s c}{2}}\right)
$$

\subsection{Long Crack Growth}

In the long crack growth the stress intensity factor, SIF, is the most important value for crack propagation. The fatigue crack propagation can be calculated with Paris's law, equation 8 [17].

$$
\frac{d a}{d N}=C \Delta K^{m}
$$

The time for long crack growth is expressed equation 7 [17]

$$
t_{l c}=\frac{2}{\left(2-m_{l c}\right) f_{C l c}(K t \Delta \sigma \sqrt{\pi})^{m_{l c}}}\left(a_{f}^{1-\frac{m l c}{2}}-a_{t h}^{1-\frac{m l c}{2}}\right)
$$

Where $a_{f}$ is the specific critical size for corrosion.
The total fatigue life may be represent by the following

\begin{tabular}{|c|c|c|}
\hline Variable & Value & Distribution \\
\hline $\begin{array}{lll}\begin{array}{l}\text { Pitting } \\
\text { (days) }\end{array} & \text { nucleation } & \text { time } \\
\end{array}$ & $\mathrm{t}_{\mathrm{pn}}=5 * 24 * 60^{2}$ & Normal \\
\hline Pitting current constant (C/s) & $\mathrm{I}_{\mathrm{p} 0}=(\mathrm{k}+1) 6.5^{*} 10^{-5}$ & Normal \\
\hline Initial pit size (m) & $\mathrm{c}_{0}=\mathrm{a}_{0}=2 * 10^{-6}$ & Normal \\
\hline $\begin{array}{l}\text { Material constant for short } \\
\text { crack growth }(\mathrm{MPa} \sqrt{ } \mathrm{m})[18]\end{array}$ & $\mathrm{c}_{\mathrm{sc}}=5 * 10^{-12}$ & Normal \\
\hline $\begin{array}{l}\text { Transition size for short } \\
\text { crack to long crack (m) }\end{array}$ & $\mathrm{c}_{\mathrm{th}}=1 * 10^{-3}$ & Normal \\
\hline $\begin{array}{l}\text { Material constant for long } \\
\text { crack growth }(\mathrm{MPa} \sqrt{ } \mathrm{m})\end{array}$ & $\mathrm{C}_{\mathrm{lc}}=5.11 * 10^{-12}$ & Normal \\
\hline
\end{tabular}
equation [17]

$$
t_{f}=\frac{t_{p g}+t_{s c}+t_{l c}+t_{p n}}{60^{2} 24}
$$

Table 4. Random variables for corrosion fatigue life

The total fatigue crack life is represented by the sum of these four phases [17]

$$
t_{f}=t_{p n}+t_{p g}+t_{s c}+t_{l c}
$$

Where $t_{p n}$ is the time for pit nucleation, $t_{p g}$ is the time for pit growth, $t_{s c}$ is the time for short crack growth $y t_{l c}$ is the time for long crack growth. The four phases are based on deterministic variables which were calculated from experimental tests and the random variables were obtained from the method of the First-Order Reliability Method (FORM) and Second-Order Reliability Method (SORM).

The probability of failure can be expressed as:

$$
\mathrm{P}_{\mathrm{f}}=\mathrm{P}\left(\mathrm{t}_{\mathrm{f}}-\mathrm{t}<0\right)=\mathrm{P}_{\mathrm{f}}\left(\mathrm{t}_{\mathrm{f}} \leq \mathrm{t}\right)
$$

\section{Results}

The Figure 5 shows the mesh of crack and Figure 6 shows the Stress Intensity Factor (SIF) in the specimens according to size of the crack. This data is used in the calculation of the time in the long crack growth. The maximum results is $\mathrm{K}_{\max }=12.4 \mathrm{MPa} * \sqrt{\mathrm{m}}$. Figure 7 shows the SIF at different cracksizes.

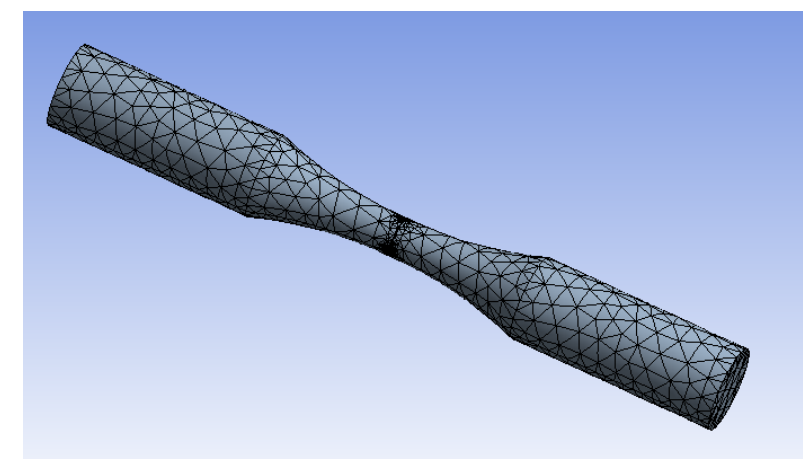

Figure 5. Mesh of crack, ANSYS ${ }^{\circledR}$

Figure 7 shows the behavior of the SIF for different crack sizes and different tests with the same data. Figure 8, Figure 9 and Figure 10 show the useful life in days with a result of 39.4 days. The mean, standard deviation and covariance are different. Through these results is possible to observe that in the Figure 6, the randomness is lower than that observed in Figure 7 and Figure 8. Thissituation shows a betterresult. 


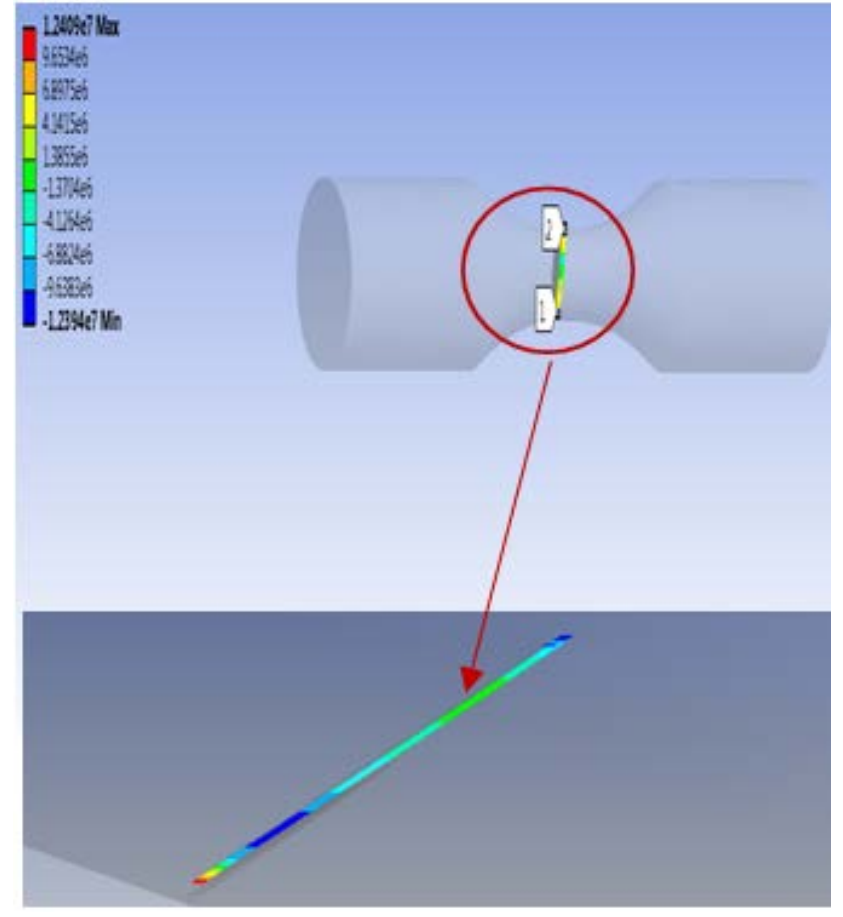

Figure 6. Stress Intensity Factor of the specimens, ANSYS ${ }^{\circledR}$

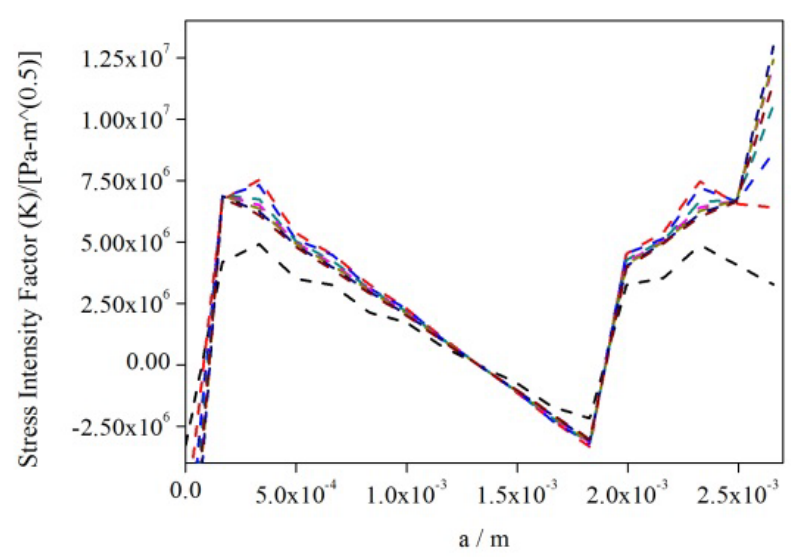

Figure 7. Different sizes of the crack

$$
\mu=39.4 \sigma=0.4 \delta=0.01
$$

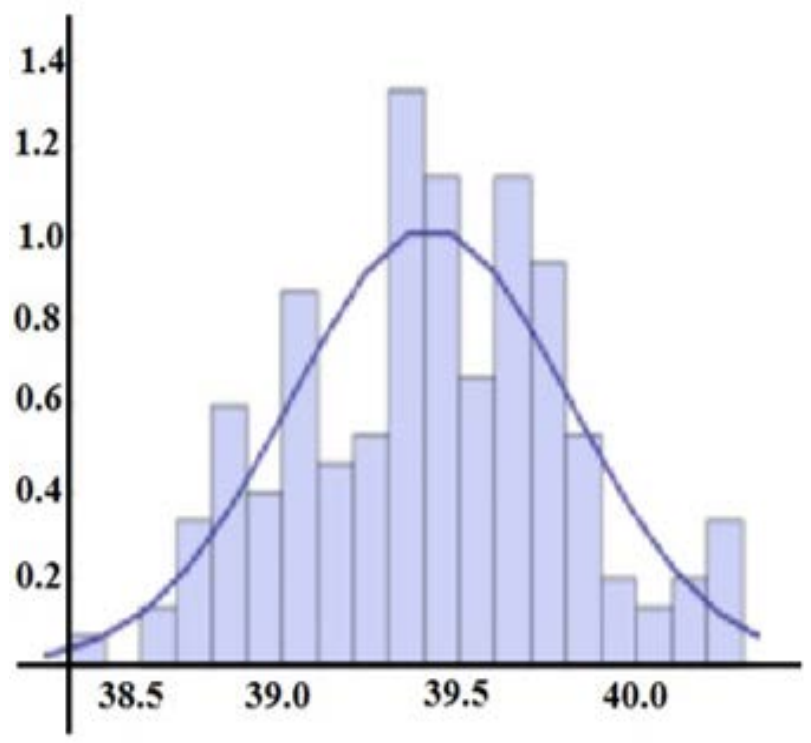

Figure 8. Time / Days. $\mu=39.4 \sigma=19.7 \delta=0.5$

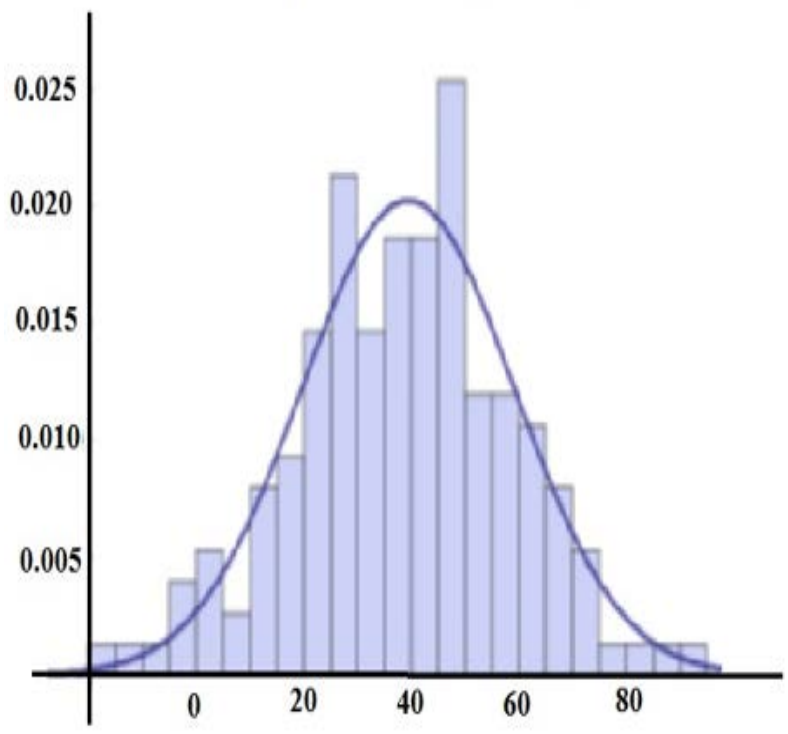

Figure 9. Time / Days.

$\mu=39.4 \sigma=37.4 \delta=0.95$

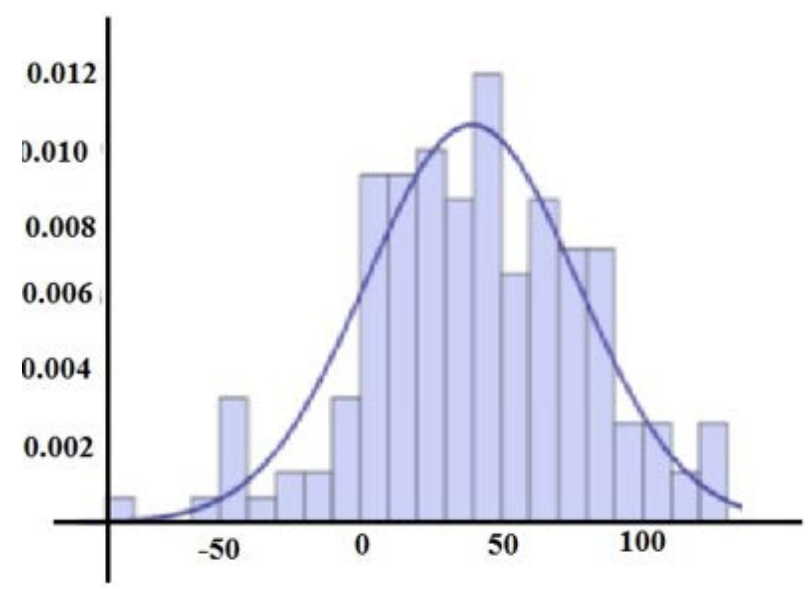

Figure 10. Time / Days.

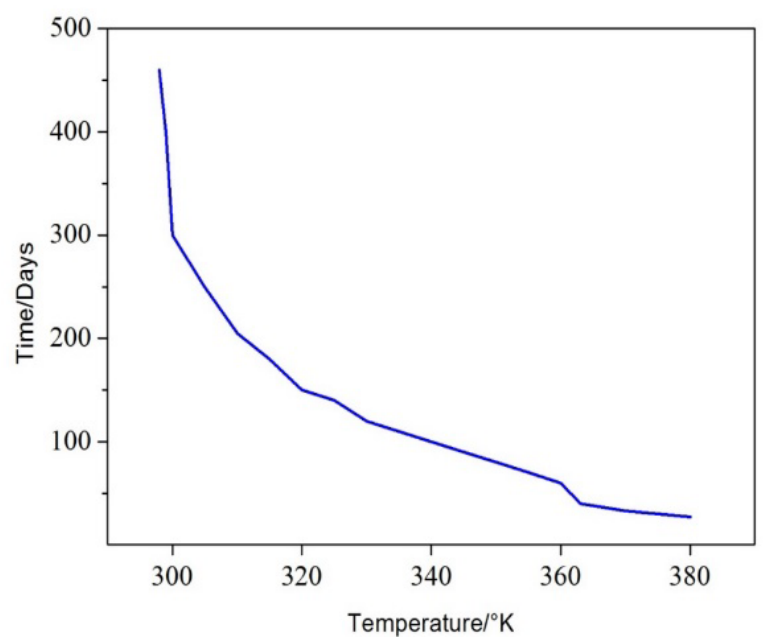

Figure 11. Relation between Temperature and Days until the failure

The Figure 11 shows the relation between temperatures in the geothermal turbine versus days until the failure. The growth in failure probability as a function of load cycles and temperature is shown for single site damage. The 
Figure 12 shows the effect of scatter (coefficient of variation, COV) of the two variables on the corrosion fatigue life.

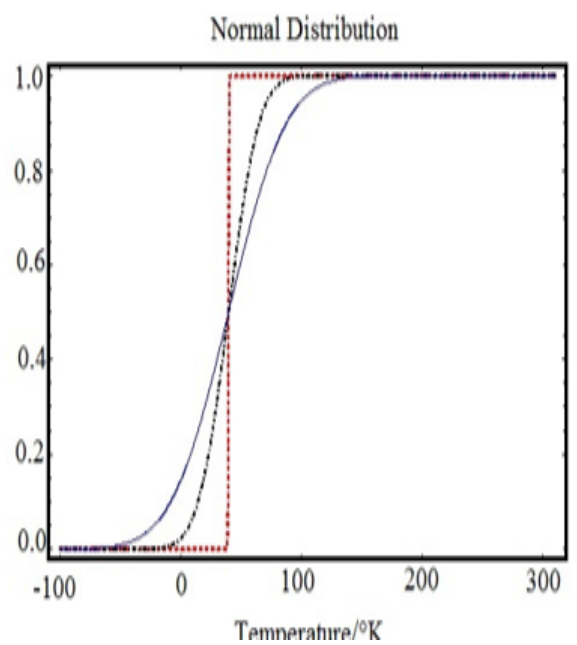

-.. $\mathrm{COV}=0.01$

... $\mathrm{COV}=0.5$

$-\mathrm{COV}=0.95$

Figure 12. Effect of scatter of the two variables on the corrosion fatigue life

\section{Conclusion}

From the physical corrosion characterization, it was observed that 410 SS without cracks suffer a mixed corrosion process in form of pitting and uniform corrosion, whereas 410 SS with cracks also suffer a mixed corrosion. Corrosion is an important failure mechanism in blades of steam turbines and leads to crack propagation. The occurrence of corrosion pits at some locations in blades is an important cause of corrosion fatigue damage. The corrosion fatigue life with temperature effect was estimated using by First-Order Reliability Method (FORM) and Second-Order Reliability Method(SORM). The results shows that the days decrease with temperature increase. The CDF values by FORM method are adequate for this problem. It shows that COV 0.01 is better because the randomness is lower.

\section{Acknowledgement}

J.A. Rodríguez, expresses his gratitude to CONACYT for the project with title is: Experimental and numerical study for evaluation of reliability and life estimation of turbine blades under resonance conditions [In Spanish] whit reference number: 156757.

\section{References}

[1] Valdéz B and Schorr M. (2013). Corrosionand preservation of industrial infrastructure.

[2] Mazur Z, García R, Aguirre J and Pérez N. (2008). Steam turbine blade failure analysis.Engineering Failure Analysis, 15 (1-2), pg 129-141.

[3] González G and Kubiak J. (2004). Diagnóstico, estimación de vidaremanente y asistenciaparaimplementarcorrecciones de lasfallas de los álabesdelúltimopaso de lasturbinasgeotérmicas de 110 y $37.5 \mathrm{mw}$.

[4] Rodríguez JA, Clemente CM., Cuevas Arteaga C., Segura JA, Urquiza G, Y.El. Hamzaoui. (2012). Estimation of useful life in turbines blades with cracks in corrosive environment. ICEFA V Fifth International Conference on Engineering Failure Analysis.

[5] Hyo J. (1998). Fatigue failure analysis of last stage blade in a low pressure steam turbine. Engineering Failure Analysis, vol. 6 pp 93-100.

[6] Otakar J and Machemer L. (2008). Steam turbine corrosion and deposits problem and solutions.Pproceedings of the thirty seventh turbomachinery symposium.

[7] Zhang XY , Li SX , Liang R , Akid R. (2013).Effect of corrosion pits on fatigue life and crack initiation. 13th International Conference on Fracture. Beijing, China.

[8] Zhou S and Turnbull A. (1999).Influence of pitting on the fatigue life of a turbine steel. Fatigue FractEngng Mater Struct, vol. 22pp 1083-1093.

[9] Dooley RB. (2007). Development of model to predict stress corrosion cracking and corrosion fatigue of low pressure turbine components

[10] Sankaran KK, Perez R, Jata KV. (2001). Effects of pitting corrosion on the fatigue behavior of aluminum alloy 7075-T6: modeling and experimental studies, Materials Science engineering, vol. A297 pp 223-229.

[11] Rajasankar J, Nagesh R. Iyer. (2006).Probability-based model for growth of corrosion pits in alluminium alloys, Engineering Fracture Mechanics, vol. 73 pp 553-570.

[12] DuQuesnay DL, Underhill PR, Britt HJ (2003).Fatigue crack growth from corrosion damage in 7075-T6511 aluminium alloy under aircraft loading. International Journal of Fatigue, Vol. 25, 371-377.

[13] Instruction Manual Model RFB-200: Rotating beam Fatigue testing Machine.

[14] Standard test method for measurement of fatigue crack growth rates ASTM E647-88A (American Society for Testing and Materials, 1988).

[15] Harlow DG and Wei RP. (1998). A probability model for the growth of corrosion pits in aluminum alloys induced by constituent particles, Engineering Fracture Mechanics, Vol. 19-3, pp 305-325.

[16] Tada H, Paul C. Paris, George R. Irwin. (2005).The stress analysis of crack handbook, Third edition, ASME, New York.

[17] Shi P and SankaranMahadevan. (2001) Damage tolerance approach for probabilistic pitting corrosion fatigue life prediction. Engineering fracture Mechanics. 1493-1507.

[18] Grosvenor AP, Kobe BA, McIntyre NS. (2005).Activation energies for the oxidation of iron by oxygen gas and water vapour, Surface Science, Vol. 574, pp 317-321.

[19] Carpinteri A, Paggi M. (2007). Are the Paris' law parameters dependent on each other, In: Proceeding of the congesso IGF19, Milano, 2-4. 